\title{
Seroprevalences and local variation of human and livestock brucellosis in two villages in Gharbia Governorate, Egypt
}

\author{
Azza El Sherbini ${ }^{\mathrm{a}, *}$, Ibrahim Kabbash ${ }^{\mathrm{b}}$, Esther Schelling ${ }^{\mathrm{c}}$, \\ Salama El Shennawy ${ }^{d}$, Nagwa Shalapy ${ }^{e}$, Gamal Hasab Elnaby ${ }^{e}$, \\ Abdel Aziz Helmy ${ }^{\mathrm{e}}$, Adel Eisa ${ }^{\mathrm{e}}$
}

\author{
${ }^{a}$ Research Unit, Tanta Fever Hospital, Taha El-Hakim St., Tanta 3111, Egypt \\ b Public Health Department, Faculty of Medicine, Tanta University, Tanta, Egypt \\ c Department of Public Health and Epidemiology, Swiss Tropical Institute, Basel, Switzerland \\ d Microbiology Department, Shebein Elkom Teaching Hospital, Shebin Elkom, Egypt \\ e Tanta Provincial Laboratory, Animal Health Research Institute, Tanta, Egypt
}

Received 4 January 2007; received in revised form 29 April 2007; accepted 30 April 2007

Available online 29 June 2007

\section{KEYWORDS \\ Brucellosis; \\ Epidemiology; \\ Risk factors; \\ Diagnostic tests; \\ Livestock; \\ Egypt}

\begin{abstract}
Summary This study aimed at assessing the epidemiology of brucellosis among both human and livestock populations in an endemic area in Egypt. A cross-sectional survey was conducted in two villages, where 616 inhabitants (aged 3-75 years) and 350 livestock of 97 households were enrolled. Sera were tested for Brucella spp. antibodies by tube agglutination test for both populations. Proportions of seropositive sera were 0.0 and $1.7 \%$ among the inhabitants, and 0.0 and $16 \%$ among livestock of villages I and II, respectively. Calculated seroprevalences considering the clustering of brucellosis within households were 0.03 for people and 5.2 for livestock in village II. The village variable $(P=0.07)$ and keeping sheep in the household $(P=0.01)$ were significant risk factors for human brucellosis, whereas only the village was significant for livestock $(P<0.001)$. Sheep showed the highest seropositive proportions of brucellosis among livestock. No association could be detected between human and livestock brucellosis. In conclusion, we found local variation of seroprevalences of brucellosis among human and livestock in the two surveyed villages. Further epidemiological studies have to be conducted in randomly selected governorates, not only to confirm the low seroprevelance of human brucellosis, but also to assess the risk factors of livestock infection for terms of prophylaxis.

(c) 2007 Royal Society of Tropical Medicine and Hygiene. Published by Elsevier Ltd. All rights reserved.
\end{abstract}

\footnotetext{
* Corresponding author. Tel.: +20 12 3442672; fax: +20 403316385.

E-mail addresses: azza_el_sherbini@yahoo.com, azza_el_sherbini@hotmail.com (A. El Sherbini).
} 


\section{Introduction}

Brucellosis is a zoonosis that is transmittable from animals to humans through contaminated milk, raw milk products or direct contact with infected animals. Although brucellosis in domestic animals has been controlled in most developed countries, it remains an important public and animal health problem in several parts of the world, including the Middle East (Tsolia et al., 2002).

Gharbia Governorate is located in the centre of the Nile Delta and has a population of nearly 4 million (which corresponds to $6 \%$ of the total Egyptian population). Two-thirds of the governorate's inhabitants belong to a rural community, in which people commonly live in close contact with their livestock. Gharbia is among the governorates with highly reported numbers of laboratory-confirmed brucellosis through passive surveillance (Ministry of Health and Population, 2002). The epidemiology of brucellosis in people and their livestock is still not properly understood, and available data are limited in Egypt and abroad (FAO, 2003).

Aims of this study were to estimate seroprevalences and potential risk factors of brucellosis in people and their livestock, and to assess the relationship between both populations. We have set up a team of physicians, epidemiologists and veterinarians to integrate different disciplines in research and to promote public health education for brucellosis.

\section{Materials and methods}

\subsection{Study design and selection of villages}

A cross-sectional survey was conducted in 2003 in two villages, Kafr Sobtas (village I) and Mansheit El-Aokaf (village II), in the catchment zone of Tanta Fever Hospital in Gharbia Governorate. Criteria for inclusion of the villages were easy accessibility for the study team and a population size of approximately 5000 in each village.

\subsection{Sample size}

In the Nile Delta, previous reports of seroprevalences of brucellosis among populations at risk ranged between 11\% (Refai, 2002) and 26\% (Fouad et al., 1996). Consequently, at $95 \%$ confidence level and $5 \%$ precision, the target sample size was calculated to be 300 inhabitants from each village (Kirkwood, 1987).

\subsection{Study population and sampling}

Each village was divided into small clusters from which one house was randomly selected. The eldest family member of the selected house was asked to participate in the study after he had been informed of its objectives. Household members (aged $\geq 3$ years) and their livestock were enrolled until the sample size was achieved.

Sixteen per cent of families in village I, and $4 \%$ of families in village II, were unwilling to participate in the study because they were unhappy about blood sampling.

\subsection{Experimental methods}

Public health education had been conducted in all visited households. A standardized questionnaire was completed for demographic data and potential risk factors of brucellosis for each inhabitant and livestock in the household. As soon as the laboratory results were available, participants who had antibodies against Brucella spp. were referred to Tanta Fever Hospital for clinical examination and possible treatment.

\subsection{Laboratory tests}

Blood samples $(5 \mathrm{ml})$ were collected from both humans and livestock. These were immediately transferred to Tanta Fever Hospital and Tanta Provincial Laboratory of Animal Health Research Institute for laboratory tests.

Human sera were subjected to the tube agglutination test (TAT) (stained Brucella suspension for B. abortus and $B$. melitensis; Murex Biotech Ltd, Dartford, Kent, UK). Sera were diluted from $1 / 80$ to $1 / 10250$ to overcome the prozone phenomenon. A positive titre $\geq 1 / 160$ was used to classify seropositive cases according to Mackie and McCartney (1996).

Livestock sera were subjected to the rose bengal panel test and buffered acidified plate antigen as screening tests. The TAT (positive titre $\geq 1 / 40$ ) and rivanol tests were used for confirmation, as reported by Alton et al. (1988). These four tests were donated from the Abassia Veterinary Research Institute, Cairo, Egypt.

\subsection{Statistical analysis}

Questionnaires and laboratory data were entered in Epilnfo software version 6.04 (CDC, Atlanta, GA, USA). Data analyses were done with Intercooled STATA 8.2 for Windows (STATA Corp., College Station, TX, USA). Explanatory variables were tested for their associations with the sero status by $\chi^{2}$ test or, where appropriate, by Fisher's exact test.

All variables were tested for association with seropositivity by a logistic regression model including a random effect on the household level. A backward stepwise selection was used at a removal level for covariates of $P=0.1$, which was based on the likelihood ratio test. To analyse the interaction between seropositivity among people and livestock within households, a generalized linear latent and mixed model was used as described by Rebe-Hesketh (2001).

\subsection{Ethical considerations}

The study fulfilled the guidelines of the 1975 Declaration of Helsinki for ethics in human research. Written consent was signed by each participant or the guardian of children.

\section{Results}

A total of 616 inhabitants were enrolled from 46 and 51 households in villages I and II, respectively, with a range of 2-16 and a median of 6 inhabitants per household. In parallel, 350 samples were taken from livestock of 43 
Table 1 Seroprevalences of Brucella spp. in people and their livestock in village II in Gharbia Governorate, Egypt

\begin{tabular}{|c|c|c|c|c|c|c|c|c|}
\hline & \multicolumn{4}{|c|}{ Household prevalences ${ }^{a}$} & \multicolumn{4}{|c|}{ Individual prevalences ${ }^{\mathrm{b}}$} \\
\hline & $n^{c}$ & Pos. & Prev. & $95 \% \mathrm{Cl}$ & $n$ & Pos. (\%) & Prev. & $95 \% \mathrm{Cl}$ \\
\hline People & 51 & 3 & 5.9 & $1-16$ & 303 & $5(1.7)$ & 0.03 & $0-3$ \\
\hline All livestock & 40 & 14 & 35.0 & $21-52$ & 159 & $25(15.7)$ & 5.2 & $1-20$ \\
\hline Cattle & 33 & 8 & 24.2 & $11-42$ & 77 & $12(15.6)$ & 4.6 & $1-28$ \\
\hline Buffalo & 25 & 5 & 20.0 & $7-41$ & 35 & $5(14.3)$ & 14.3 & $6-30$ \\
\hline Sheep & 11 & 2 & 18.2 & $2-52$ & 29 & $6(20.7)$ & {$[0]^{d}$} & $0-1^{d}$ \\
\hline Goats & 16 & 2 & 12.5 & $2-38$ & 18 & $2(11.1)$ & 10.7 & $3-35$ \\
\hline
\end{tabular}

a Binomial confidence intervals.

b Prevalences and confidence intervals calculated with a random error on the household level to consider clustering of seropositive individuals within households.

c People were sampled in all enrolled households in the study and livestock were sampled in $86 \%$ of the total number of households.

${ }^{d}$ High clustered occurrence: each three positive sheep in households where 12 and three sheep have been examined, respectively.

households in village I and 40 households in village II, with a range of 1-13 and a median of 4 animals per household; the remaining households had no livestock at the time of blood sampling.

Village II harboured the five seropositive human cases (1.7\%), aged $14-50$ years, living in three households, and the 25 seropositive livestock, which were found in 14 households. Table 1 shows the household and individual seroprevalences of brucellosis.
The human seropositive case with the highest antibody titre $(1 / 2560)$ was a shepherd. The five seropositive people had a history of brucellosis treatment during the past year and were found healthy by clinical examination. Titres of TAT in the livestock were 1/20 (four cows with positive results in the other three tests), 1/40 (six cows, two buffalos), 1/80 (two cows, three buffalos, four sheep, two goats) and 1/160 (two sheep) (data are not tabulated). Livestock in both villages were local breeds and none of them had

Table 2 Comparison of human demographic data between two study villages in Gharbia Governorate, Egypt

\begin{tabular}{|c|c|c|c|c|c|c|}
\hline \multirow[t]{2}{*}{ Variable } & \multirow[t]{2}{*}{ Category } & \multicolumn{2}{|c|}{ Village I $n=313$} & \multicolumn{2}{|c|}{ Village II $n=303$} & \multirow[t]{2}{*}{$p a$} \\
\hline & & $n$ & $\%$ & $n$ & $\%$ & \\
\hline \multirow[t]{2}{*}{ Sex } & Males & 147 & 47 & 138 & 46 & \\
\hline & Females & 166 & 53 & 165 & 54 & 0.7 \\
\hline \multirow[t]{3}{*}{ Age class (years) } & $<15$ & 58 & 19 & 82 & 27 & 0.01 \\
\hline & $15-45$ & 181 & 58 & 173 & 57 & \\
\hline & $>45$ & 72 & 23 & 48 & 16 & \\
\hline \multirow{3}{*}{ Occupation (hazard) ${ }^{\mathrm{b}}$} & High & 61 & 20 & 58 & 19 & 0.2 \\
\hline & Moderate & 91 & 29 & 108 & 36 & \\
\hline & Low & 161 & 51 & 137 & 45 & \\
\hline Previous hospitalization ${ }^{c}$ & Yes & 6 & 2 & 11 & 4 & 0.2 \\
\hline Suspected relative with brucellosis ${ }^{c}$ & Yes & 39 & 13 & 78 & 26 & $<0.001$ \\
\hline Raw milk consumption & Yes & 251 & 80 & 269 & 89 & $<0.01$ \\
\hline \multirow[t]{3}{*}{ Dairy product consumption ${ }^{d}$} & None & 29 & 9 & 12 & 4 & \multirow[t]{3}{*}{$<0.01$} \\
\hline & One product & 10 & 3 & 3 & 1 & \\
\hline & All products & 270 & 87 & 272 & 95 & \\
\hline Keeping cattle & Yes & 228 & 73 & 239 & 79 & 0.08 \\
\hline Keeping buffalo & Yes & 237 & 76 & 246 & 81 & 0.1 \\
\hline Keeping sheep & Yes & 85 & 27 & 114 & 38 & 0.005 \\
\hline Keeping goats & Yes & 213 & 68 & 158 & 52 & $<0.001$ \\
\hline History of aborted livestock in the household & Yes & 66 & 21 & 72 & 24 & 0.4 \\
\hline
\end{tabular}


Table 3 Risk factors for human brucellosis in two study villages in Gharbia Governorate, Egypt

\begin{tabular}{|c|c|c|c|c|c|c|}
\hline \multirow[t]{2}{*}{ Variable } & \multirow[t]{2}{*}{ Category } & \multicolumn{2}{|c|}{ Seronegative $n=611$} & \multicolumn{2}{|c|}{ Seropositive $n=5$} & \multirow[t]{2}{*}{$p^{a}$} \\
\hline & & $n$ & $\%$ & $n$ & $\%$ & \\
\hline \multirow[t]{2}{*}{ Sex } & Males & 283 & 46 & 2 & 40 & \\
\hline & Females & 328 & 54 & 3 & 60 & 1 \\
\hline Age & $<15$ & 139 & 23 & 1 & 20 & \\
\hline class & $15-45$ & 351 & 58 & 3 & 60 & \\
\hline (years) & $>45$ & 119 & 19 & 1 & 20 & 1 \\
\hline \multirow[t]{2}{*}{ Village } & 1 & 313 & 51 & 0 & 0 & \\
\hline & II & 298 & 49 & 5 & 100 & 0.03 \\
\hline Raw milk consumption & Yes & 515 & 84 & 5 & 100 & 1 \\
\hline Dairy product consumption & Yes & 546 & 89 & 5 & 100 & 1 \\
\hline Keeping cattle & Yes & 463 & 76 & 4 & 80 & 1 \\
\hline Keeping buffalo & Yes & 479 & 78 & 4 & 80 & 1 \\
\hline Keeping sheep & Yes & 194 & 32 & 5 & 100 & 0.003 \\
\hline Keeping goats & Yes & 367 & 60 & 4 & 80 & 0.65 \\
\hline
\end{tabular}

a Fisher's exact test.

Table 4 Results of two backward stepwise random-effect logistic regression analyses of potential risk factors for brucellosis in 250 female livestock and in 613 people in Gharbia Governorate, Egypt

\begin{tabular}{|c|c|c|c|c|c|}
\hline & Risk factor & Category & Seronegative $n=229$ & Seropositive $n=21$ & $P\left(\mathrm{LR}^{2}\right)^{\mathrm{a}}$ \\
\hline \multirow[t]{3}{*}{ Livestock } & Village & I & 123 & 0 & \\
\hline & & II & 106 & 21 & $<0.001$ \\
\hline & & & Seronegative $n=608$ & Seropositive $n=5$ & \\
\hline \multirow[t]{4}{*}{ People } & Keeping sheep & No & 417 & 0 & \\
\hline & & Yes & 194 & 5 & 0.01 \\
\hline & Village & I & 313 & 0 & \\
\hline & & II & 298 & 5 & 0.07 \\
\hline
\end{tabular}

a $P\left(\operatorname{LR} \chi^{2}\right)=$ likelihood-ratio $\chi^{2}, P$-value based on goodness of fit of the model [difference of the deviance $(-2$ log likelihood) with the intercept only and that of the final model].

been vaccinated against brucellosis, which was not compulsory.

Table 2 shows significant differences of demographic data between both villages. Regarding seropositive livestock, older animals $(P=0.03)$ and the village variable $(P<0.001)$ were significant risk factors by univariate analysis (data are not shown). The village variable and keeping sheep in the household were significant risk factors for brucellosis among people (Table 3).

Logistic regression analysis revealed the village variable as significantly $(P<0.1)$ associated with seropositive livestock. The village and keeping sheep were significantly associated with seropositive people for brucellosis (Table 4). No significant correlation was found between human brucellosis sero status and household proportions of seropositive livestock, small ruminants or sheep (data not shown).

\section{Discussion}

The low proportions of seropositive human brucellosis in the surveyed villages were surprising when compared with $11 \%$ (Refai, 2002) and 26\% (Fouad et al., 1996) among at-risk groups in the Nile Delta. Our result could be explained by the inclusion of low, moderate and high hazard groups in this study. Previous human brucellosis studies have not tested for seroprevalences in the livestock, and one can presume that seroprevalences in livestock were higher there.

Yet, further epidemiological studies have to be conducted in randomly selected governorates to reach a firm conclusion about the public health relevance of brucellosis in our region.

Proportions of seropositive livestock in village II were higher than those found in other surveys, with 1.7, 0.8 and $1.1 \%$ as well as 2, 8 and $6 \%$ for cattle, buffalo and sheep, respectively (El-Gamaei and El-Gamal, 1995; Meabed and ElBatanony, 1998). However, this was less than the $29 \%$ among cattle that had been reported by Abou-Zaid and Mehanna (1998) in different governorates in Egypt.

Local variation in the level of development between both villages had been observed during the fieldwork. Village II did not have available tap water most of the time and lacked sewage disposal in the households, and there was no health-care unit. It was reported that usage of tap water for watering sheep flocks was a protective factor for brucellosis seropositivity compared with usage of well and spring 
water (Al-Talafhah et al., 2003). Besides, the significant differences between the two villages for human demographic variables are seemingly in line with our observation about local variation as a significant risk factor for brucellosis.

The clustering of seropositive people and sheep within a few households could be partly explained by sharing the same risk factors within the households. Household as a risk factor was reported in Saudi Arabia, where brucellosis seropositivity was $13 \%$ for household members and $42 \%$ for families having an index case (Almuneef et al., 2004).

We could not detect a significant association between seropositive cases in people and livestock within households, but this might be due to the low number of positive human cases. Schelling et al. (2003) did not find a significant correlation for a dynamic intermixing of people and their livestock in nomadic camps in Chad.

The association between keeping sheep and human brucellosis has also been found as the major risk factor for this zoonosis in our case-control study (El Sherbini et al., 2005). Several reports claim sheep to have the highest proportion of brucellosis infection among livestock (Almuneef et al., 2004; Al-Shamahy et al., 2000). Moreover, infected sheep with brucellosis could still have successful pregnancies after, or without, previous abortion (Roberts, 1971).

The non-significant association between consumption of raw milk and dairy products and brucellosis in the current study might be explained by the small number of positive cases. Yet such results are in agreement with of our previous study (El Sherbini et al., 2005), although they disagree with those of Almuneef et al. (2004), Al-Shamahy et al. (2000) and Al-Talafhah et al. (2003), indicating that risk factors for brucellosis must be assessed in each community to identify the most appropriate control and prevention measures.

The titre of $1 / 20$ among the livestock was taken as the positive cut-off for brucellosis, unlike in previous studies such as that by Alton et al. (1988). According to our experience, that titre represents good evidence for previous livestock infection.

Based on these results, we recommend the development of basic infrastructure in all villages, promoting health education among the at-risk groups and providing vaccination against brucellosis, particularly for sheep in underdeveloped villages.

In conclusion, this community-based study showed rather low seroprevalence of brucellosis among people and a clustering of seropositive livestock in the village with poor infrastructure compared with the village with a better infrastructure. Human brucellosis was mainly related to keeping sheep in the household. Further epidemiological studies of brucellosis should be conducted in other governorates for setting up priorities for control measures.

Authors' contributions: AES and IK designed the study and conducted the field research among humans; IK led the public health promotion during the field study; SES carried out the laboratory tests among humans; NS, GHE, AAH and AE carried out the field research and laboratory tests among livestock; ES conducted the statistical analysis; AES and ES interpreted the data and wrote the manuscript. All authors read and approved the final version. AES is guarantor of the paper.

Acknowledgement: We would like to thank Mr Mohamed Yonis for assistance in the serological tests of this study.

Funding: This investigation No. SGS.02/82 received technical and financial support from the joint WHO/EMRO/ DCD/TDR Small Grants.

Conflicts of interest: None declared.

Ethical approval: Ethical Committee of the Tanta Fever Hospital, Gharbia Governorate, Egypt.

\section{References}

Abou-Zaid, A.A., Mehanna, A.A., 1998. Evaluation of some diagnostic tests for brucellosis in cattle. Vet. Med. J. Giza 48, 319328.

Almuneef, M., Memish, Z., Balkhy, H., Alotaibi, B., Algoda, S., Abbas, M., Alsubaie, S., 2004. Importance of screening household members of acute brucellosis cases in endemic areas. Epidemiol. Infect. 132, 533-540.

Al-Shamahy, H.A., Whitty, G.M., Wright, S.G., 2000. Risk factors for human brucellosis in Yemen: a case control study. Epidemiol. Infect. 125, 309-313.

Al-Talafhah, A.H., Lafi, S.Q., Al-Tarazi, Y., 2003. Epidemiology of ovine brucellosis in Awassi sheep in Northen Jordan. Prev. Vet. Med. 60, 297-306.

Alton, G.G., Jones, L.M., Angus, R.A., Vergen, I.M., 1988. Techniques for Brucellosis. Laboratory Institute National de La Recherche Agronomique, Paris.

El-Gamaei, S.R., El-Gamal, A.M., 1995. Incidence of brucellosis among farm animals in Dagahlia governorate. Zagazig Vet. J. 23, 19-24.

El Sherbini, A., Kabbash, I., Bassili, A., El-Shennawy, S., El-Assal, M., El-Saied, N., 2005. Risk factors and diagnostic criteria of brucellosis in an endemic area in Egypt. Infect. Dis. Clin. Pract. 13, 295-300.

FAO, 2003. Guidelines for coordinated human and animal brucellosis surveillance FAO Animal Production and Health, paper no. 156, Rome, p. 56.

Fouad, K., Nour El-Din, A., Salah, A., Murad, A., 1996. Study of Brucella infection as an occupational risk among abattoir workers in Alexandria. Bull. Alex. Fac. Med. 32, 299-306.

Kirkwood, B.R., 1987. Calculation of required sample size in medial statistics, in: Kirkwood, B.R. (Ed.), Medical Statistics. Blackwell Scientific, Oxford, pp. 191-200.

Mackie, A., McCartney, E. (Eds.), 1996. Practical Medical Microbiology, Vol. II. Churchill Livingstone, New York, p. 477.

Meabed, M.H., El-Batanony, M.M., 1998. Childhood brucellosis in Beni-Suef governorate: preliminary study conducted in a fever hospital during the period 1995-1998. Gazzit. Egypt Pediat. 46, 195-202.

Ministry of Health and Population, 2002. Official Report of Fever Hospitals Administration. Ministry of Health and Population, Cairo.

Rebe-Hesketh, S., 2001. GLLAMM Manual Technical Report 2001/01. Department of Biostatistics \& Computer. Institute of Psychiatry, Kings College, University of London, London. 
Refai, M., 2002. Incidence and control of brucellosis in the Near East region. Vet. Microbiol. 90, 81-110.

Roberts, S.J., 1971. Infertility in male animals, in: Roberts, S.J. (Ed.), Veterinary Obstetrics and Genital Diseases, second ed. Edward Brothers, Ann Arbor, MI, p. 683.

Schelling, E., Diguimbaye, C., Daoud, S., Nicolet, J., Boerlin, P., Tanner, M. , Zinsstag, J., 2003. Brucellosis and Q-fever seropreva- lences of nomadic pastoralists and their livestock in Chad. Prev. Vet. Med. 61, 279-293.

Tsolia, M., Drakonaki, S., Messaritaki, A., Farmakakis, T., Kostaki, M., Tsapra, H., Karpathios, T., 2002. Clinical features, complications and treatment. Outcome of childhood brucellosis in central Greece. J. Infect. 44, 257262. 